\title{
HISTORIA: Filling the Gap of Time and Space
}

\author{
$\operatorname{AUTHOR}(\mathrm{S})$ :
}

Tosa, Naoko; Konoike, Ryotaro; Nakatsu, Ryohei; Swale, Alistair

\section{CITATION:}

Tosa, Naoko ...[et al]. HISTORIA: Filling the Gap of Time and Space. 2011 International Conference on Culture and Computing 2011: 157-158

\section{ISSUE DATE:}

2011.10

URL:

http://hdl.handle.net/2433/250229

\section{RIGHT:}

(c) 2011 IEEE. Personal use of this material is permitted. Permission from IEEE must be obtained for all other uses, in any current or future media, including reprinting/republishing this material for advertising or promotional purposes, creating new collective works, for resale or redistribution to servers or lists, or reuse of any copyrighted component of this work in other works.; この論文は出版社版でありません。引用の際には出版社版をご確認ご利用ください。;This is not the published version. Please cite only the published version. 


\section{Historia:Smart Phone AR Art apprication for connect time and space by Historial icon and Modarn Manga Icon}

\author{
Naoko Tosa \\ Academic Center for Computing \\ and Media Studies \\ Kyoto University \\ Kyoto, Japan \\ e-mail:tosa@media.kyoto-u.ac.jp
}

\author{
Ryotaro Konoike \\ Department of engineering \\ Kyoto University \\ Kyoto, Japan \\ e-mail:konoike@qoe.kuee.kyoto- \\ u.ac.jp
}

\author{
Ryohei Nakatsu \\ Interactive \& Digital Media Institute \\ National University of Singapore \\ Singapore \\ e-mail: idmdir@nus.edu.sg
}

\begin{abstract}
Various kinds of icons for visual communications have been used from the very beginning of human history. We can find such various kinds of icons in wall paintings all over the world, hieroglyphs and so on. There are lots of similarities among these icons. Because of this, even though most of us are not using these icons or old characters, we have a kind of nostalgic feeling toward these old forms.

This artwork realizes the integration of various kinds of icons that have existed throughout the human history and throughout the human races jumping the gap of time and space. And these integrated icons are augmented on the actual scenery of today.

On a display of a smart phone there are various icons flowing around on the space. Users are required to write a new meaning of the icon sequence in English. The pictograph and the background are overlapped and composed in a form of snapshot.
\end{abstract}

Keywords- Art, POPculture, Manga, Icon, Symbol, Communication

\section{INTRODUCTION}

People have done visual communication from ancient times. The wall paintings of cows in various cave remain as tracks of the first visual communications of human. What was the purpose of painting these cows' pictures? Probably one of the aim it to tell people the importance and also excitement of cow hunting? Also in predecessors' wall paintings, there are many pictures about animals. Also one of the purposes of these pictures is to tell people about human action of hunting and its relationship to food and later more importantly to religion.

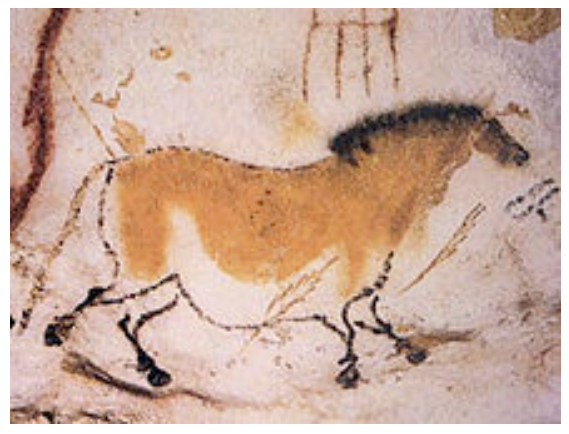

Figure 1. Ancient Cave painting
It not only drew but also the container and the doll were made from the soil, and when the age advanced, the human race developed symbols that abstract actual physical entities and made carve paintings, totem poles, etc. using these symbols. And, the forms of symbols were refined and gradually they became sign and icon. We can find such various kinds of icons in wall paintings all over the world, hieroglyphs, Celtic, Chinese characters, earthen clay figures, totem poles, masks, pattern and so on.

After such icons and signs were developed, it was discovered to use them for communications. Visual Communication is strong than language [1]. Even now in various scenes we use such icons and signs; various symbols in cartoons, emoticons used for mobile phone based communications, the national flag of the computer pictograph, and the pictogram, etc.

\section{CONCEPT OF HISTORIA}

However, the interpretation of the meaning has changed throughout the age and the place. Also icon shapes have changed a lot depending on time and place. This is a very interesting fact from cultural information perspective [2]. Taking the history of icons into consideration we have reached an idea of this artwork called "Historia." First of all, we thought that it would be interesting if by using both old icons with modern icons users could compose a message. Second idea is that those icons would be overlapped on a real space by applying Augmented Reality(AR) technologies to smart phones. And by combining these ideas the whole concept of the system is, that when users take photo at a historical place, they can compose their own message by selecting various old and new icons, that are related to the scene of the historical place, and send it to others or store it as still picture.

Usually, AR technology use simulation such as existing historic media from archives and superimpose them seamlessly on reality at the right spot [3][5]. Also AR connected storytelling technology [4]. Otherwise AR technology uses Art museum navigation [6]. We will uses AR technology use artistic and imaginative way.

This system has been proposed and accepted as artwork by this year's Venice Biennale AR Intervention. Moreover, it is scheduled to be show at Expo Digital Gallery at 
EXPO2012 that will be held in South Korea next year. The exhibition place is the main street of the Expo.

\section{HiSTORIA SYSTEM: COMPOSITE EFFECT OF PHOTO AND HISTORIAL ICON}

The target of this art work and at the same time a smart phone application program is to compose a photograph in which an arbitrary country's historical icons and cartoonlike expression is united using the technology of augmented reality. Moreover a simple message can be composed by the users using historical icons with the cartoon expression of the present age and today's emoticons and will be overlapped on the photograph. Users can take a photo, compose a message and then can send it to Twipic and Facebook. The brief flow of this system is shown below:

\section{A. The Process of Displaying Icons on AR View}

Technologies that mix real sceneries and virtual substances are called augmented reality (AR). In this system we use "Layar Augmented Reality" (referred as Layar below), which allows us to use AR technology on smartphones.

Layar Reality Browser is one of the augmented reality (AR) technologies that enables the users to see additional information (layers) on top of reality. The Layar developers can create their own contents to be published on Layar web site. The general users can search the developed layers using Layar client software on their smartphones.

(1) For this system, when users stand at a place looking around them using smart phones various kinds of icon are displayed overlapped on the surrounding scenes. These icons and the surrounding scenes are closely related by using the CGP function of smart phones. Figure 2 showed illustration and fig. 3 showed example image.

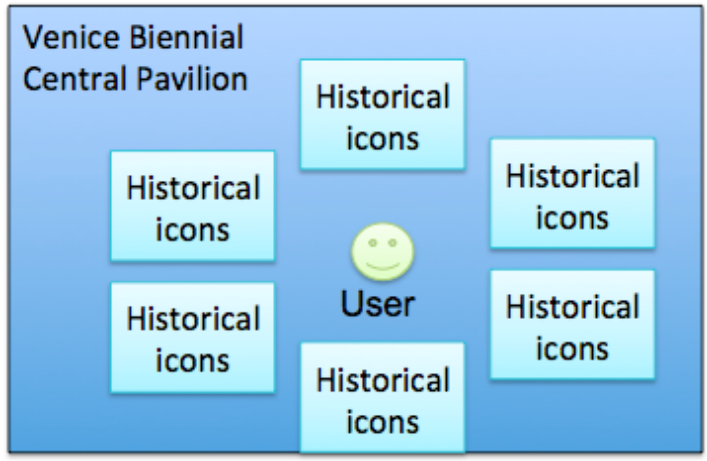

Figure 2. Various icons apper depending on the place and the direction of an user.

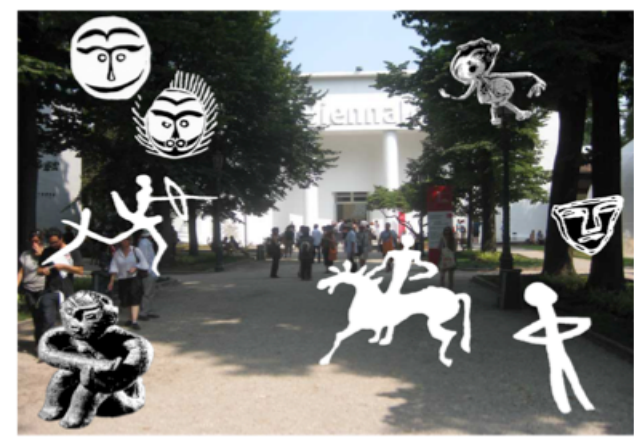

Figure 3. Exsample image at Venice biennale 2011.

(2) Icons shown on the screen are categorized in A to M, as mentioned in fig.4. These categories are mapped on specific regions in the world map.

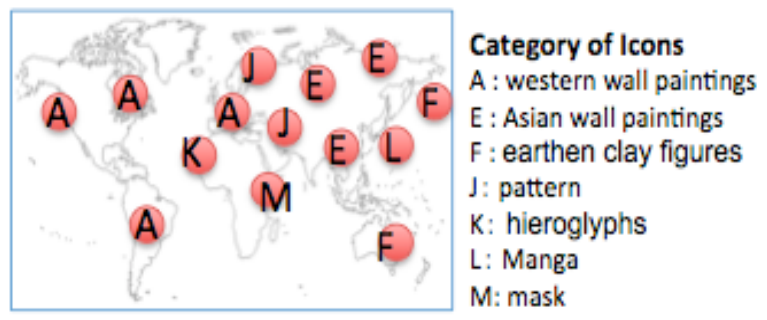

Figure 4. Seven categories of icon groups and the related resions.

(3) In addition, the categories are divided into subcategories depending on the types of animations of the icons. Different animations are used on the same categories that are mapped on different places on the world map.

(4) The positions of icons are related to the world map. Icons are shown in 'billboard' style, and they always aligns their directions to the user. The textures are animated.

(5) If the user selects one of the icon groups, then all the icons belonging to the group are reloaded. If all the icons belonging to the category cannot be shown on a display a "Change" button appears. If the user selects "Change" button, then other icons belonging to the category are loaded and shown on the display.

\section{B. The databases}

We have investigated various types of historical icons that can be found all over the world and categorized them into seven groups as shown in Fig.3. These huge among of icons are used as a database of this system.

Each icon consist of thumbnail images, icon images to be used in edit mode, and 3D model to be overlapped on real sceneries. The display size of each icon is also stored.

Typical example of icons in each category is shown in Fig. 5 to Fig.11. 

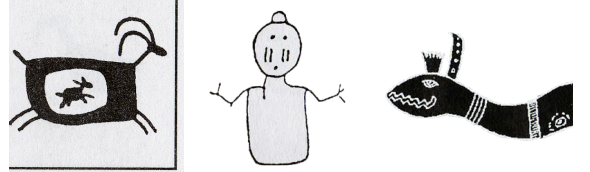

Figure 5. "A" Category of icon "Western wall paintings"
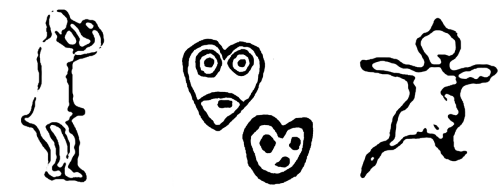

Figure 6. "E" Category of icon "Asian wall paintings"
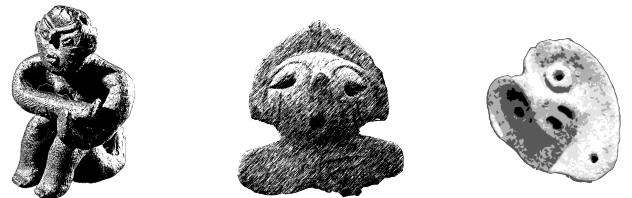

Figure 7. "F" Category of icon "Earthen clay figures"

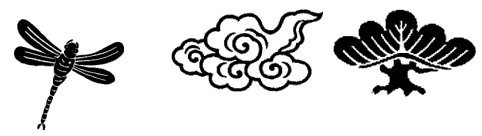

Figure 8. "J" Category of icon "Pattern"
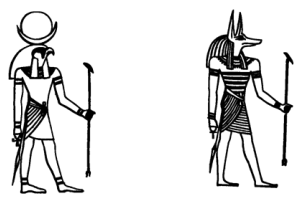

Figure 9. "K" Category of icon "Hieroglyphs"
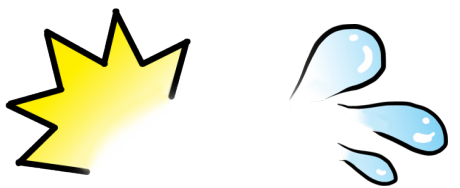

Figure 10. "L" Category of icon "Japanese Manga"

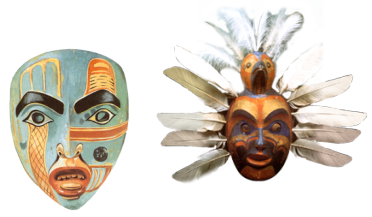

Figure 11. "M" Category of icon "Mask"
There are other categories that include such special icons as "Emoticon" (icons used for expressing emotions), Flags and "Decome" (Japanese term for picture characters or emoticons used in Japanese e-mails.) that are shown in edit mode. The system saves the history of user's selection and submitted messages for later use.

\section{DetAiled PROCESS OF THE INTERACTION}

A. We will showed example of interaction.

(1) Launch Historia: The user searches and launch "Historia" using Layar client software on his / her smartphone (fig.12).

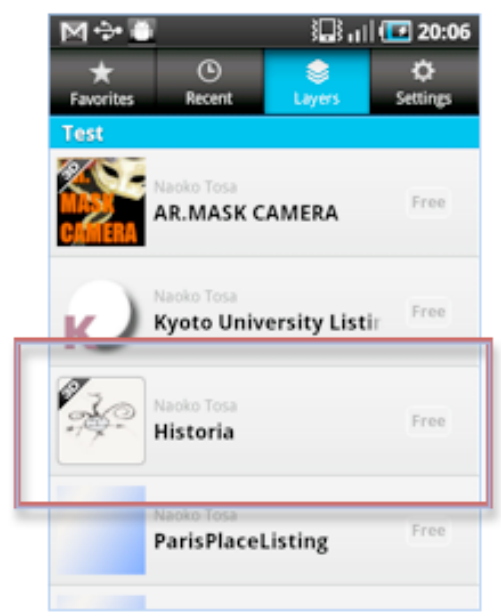

Figure 12. Menu of Historia

(2) Display of icons: Using the GPS function of a smart phone the system can identify the place and the direction of the user. The relationship between the seven icon categories and these location information cons are shown in Augmented Reality (AR): Icons mapped on the world map (fig.4) are shown on the real images from the camera of smartphone (fig.13).

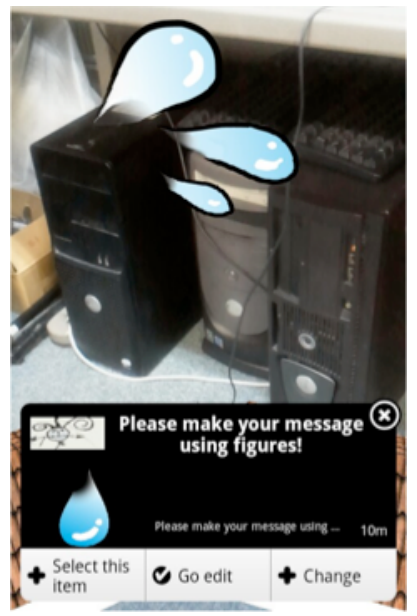

Figure 13. Composition of a message by selecting icons. 
(3) Composing a message using icons : The user selects sequentially several icons shown on the display and compose his/her own message. The selection is done by tapping "Select this item" button (Fig.13).

(4) Editing the message: Then the user can tap "Go edit" button to see his/her selection. He/she can also edit the message using edit tools on top of the screen (Fig.14). Below are the several functions used in the edit mode.

A) "Insert" tool allows you to insert new icons from "Emoticons," "Flags" and "Decomes." (Fig.14)

B) "Del" tool allows you to delete one icon or delete all icons from the selection.

C) "Sort" tool allows you to sort icons of the selection.

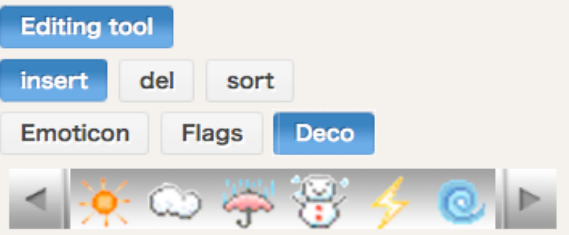

Tap figures to insert, then they will added behind the figures.

Figure 14. Launching of Historia

(5) Submitting comments: The user can submit comments to the message. These comments are text messages and will be used to give additional information or to clarify the meaning of the messages composed as a sequence of icons. Then the user taps "Submit" button to submit the message and comment.

(6) Showing message in AR mode: The user's message as well as the comment appears on the display overlapped on the taken photo.

(7) Taking the screen shot: The user can take a screen shot using the Layar client's functionality.

(8) Sharing in the photo on Facebook: The user can share the screen shot through the Historia fanpage in Facebook.

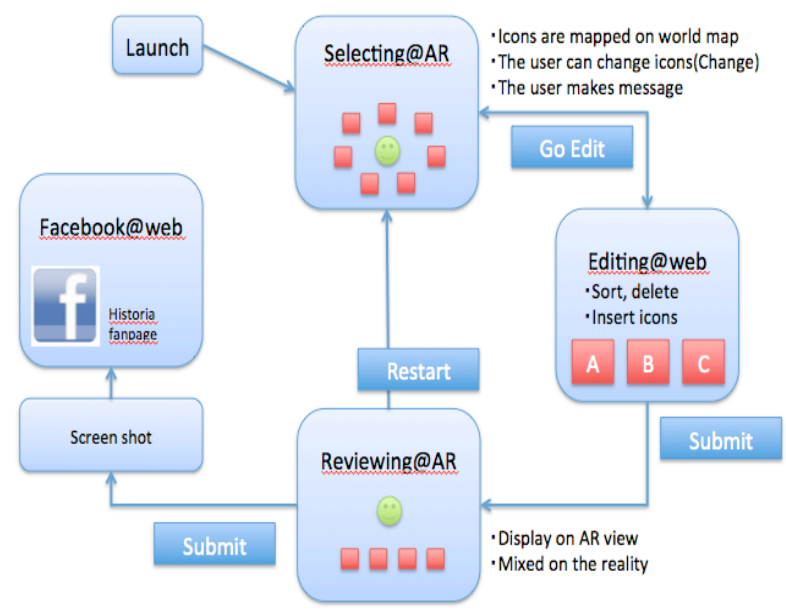

Figure 15. System construction of Historia

\section{B. System costruction}

The construction of the whole system is shown in Fig.15. As the structure of the system and the function of each subsystem well corresponds each of the interaction processes described above. Therefore the detailed explanation of the system construction is omitted here.

\section{Showed at Venice Bennale 2011}

We showed Historia as AR intervention at Venice Bennale 2011. The AR pavilions at the 54th Biennial reflect on a rapidly expanding and developing new realm of Augmented Reality Art that radically crosses dimensional, physical and hierarchical boundaries.[1]. We showed several message follows (fig.16).
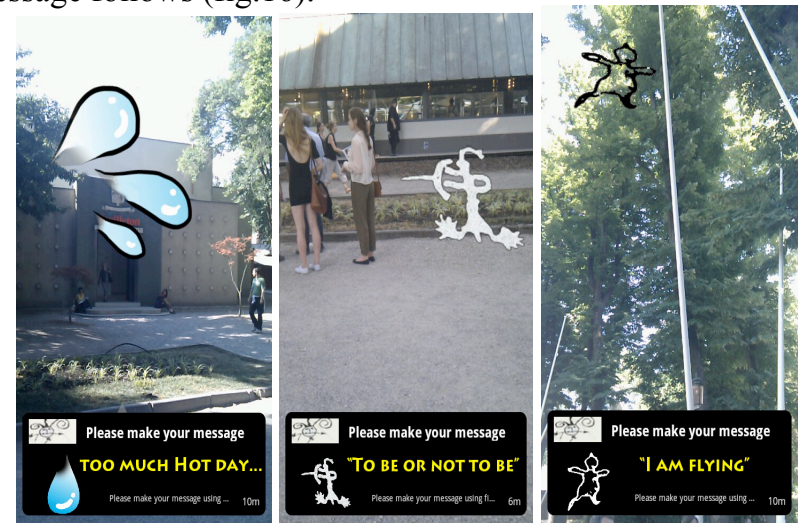

Figure 16. Snapshot Historia at Vennice Beinnale

\section{KOREA EXPO 2012 PLAN}

We are examining the application of this Historia system to the exhibition at Expo Digital Gallery at EXPO2012 held in Korea next year.

In Expox2012, four traditional gods' images will be projected to the ceiling. These gods are dragon, tiger, turtle, and phoenix and they are traditional gods in Asian history, we are studying how to modify the basic function of Historia to this exhibits including new icon groups to be prepared. Below are the overall ideas of this new exhibit.

\section{A. Interaction}

1. Azure Dragon appears on the ceiling screen and users can see it through their smart phone. (Fig. 17.)

2. Historical icons appear on the smart phone, if visitors watch the dragon through their smart phone. These icons will vary depending on the users' country. 


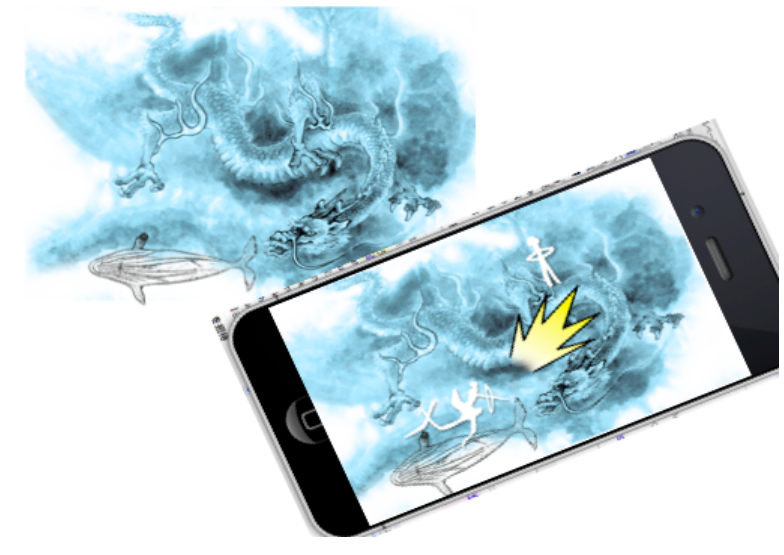

Figure 17. Azure Dragon on a smart phone as well as on a ceiling.

The remaining interaction process is somehow similar to the present Historia and will not be described here. The whole interaction process is summarized in Fig. 18

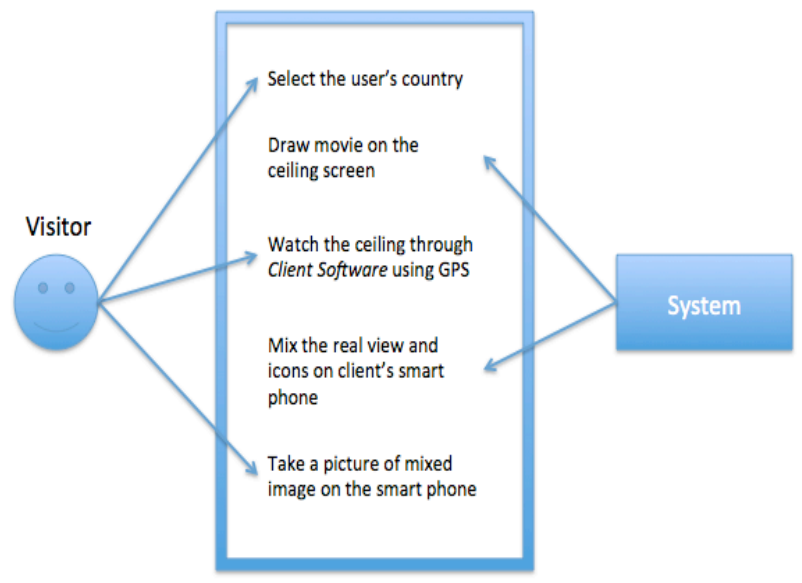

Figure 18. Interaction process.

\section{B. Block Diagram}

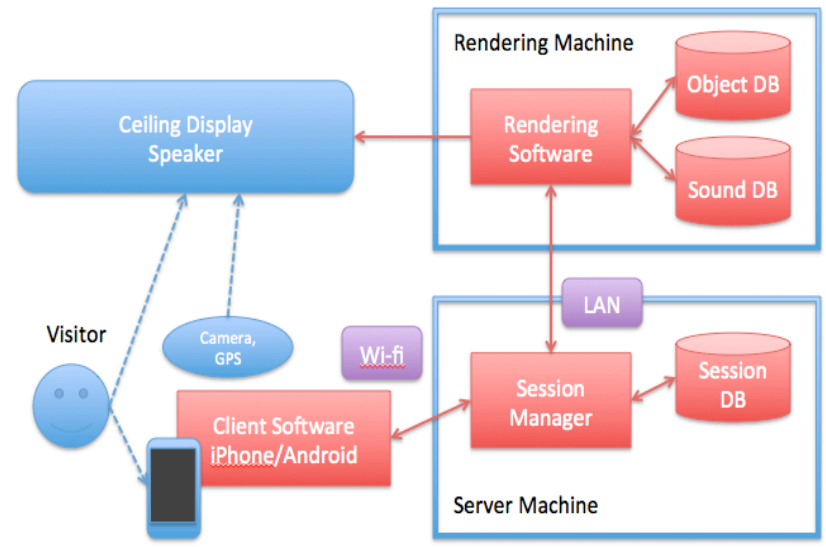

Figure 19. Interaction process
The block diagram of the whole system is shown in Fig. 19. As the whole structure of the system is similar to Historia the detailed description of the system will be omitted here and will be reported in separate paper.

\section{CONCLUSION}

In this paper we have described the basic concept of our art \& technology work called Historia and also described the detailed mechanism of the work. Originally this system has been developed as an artwork for At Expo Digital Gallery in EXPO2012 that will be held in South Korea, how the meaning is given and the icon of the image and Historia is synthesized are researched.

In the future, by extending this system we want to study new type of nonverbal communication method that uses art as a basic methodology to transfer message and want to merge such new function with the present SNs such as Facebook and Twitter.

\section{Reference}

[1] Babbitt Kline, T.J.; Ghali, L.M.; Kline, D.W.; Brown, S.; Visibility distance of highway signs among young, middle-aged, and older observers: icons are better than text.: Human factors (0018-7208) 1990 Oct. Vol.32,No.5;p.609-19

[2] Shin, YW.; Objects and their icons in the brain: The neural correlates of visual concept formation: NEUROSCIENCE LETTERS (03043940) 2008. Vol.436,No.3;p.300-304

[3] Zoelliner, M.; Cultural Heritage Layers: Integrating Historic Media in Augmented Reality: 2009 15TH INTERNATIONAL CONFERENCE ON VIRTUAL SYSTEMS AND MULTIMEDIA PROCEEDINGS (VSMM 2009) 2009. p.193-196

[4] Wither, J.; Allen, R.; Samanta, V.; Hemanus, J.; Tsai, Y.-T.; Azuma R.; Carter, W.; Hinman, R.; Korah, T.; The Westwood experience: Connecting story to locations via mixed reality: 9th IEEE International Symposium on Mixed and Augmented Reality 2010: Arts, Media, and Humanities, ISMAR-AMH 2010 - Proceedings (2010). p.39

[5] Michael, D.; Comparative Study of Interactive Systems in a Museum: DIGITAL HERITAGE (0302-9743) 2010. Vol.6436;p.250-261

[6] Nassar, M.A.; Meawad, F.; An augmented reality exhibition guide for the iphone: Proceedings - 2010 International Conference on User Science and Engineering, i-USEr 2010. p.157

[7] http://www.manifestar.info/venicebiennial2011/ 